Journal of Agrometeorology 23 (4) : 442-451 (December 2021) : https://doi.org/10.54386/jam.v23i4.161

\title{
Farmer's perception of climate change and adaptation strategies under temperate environmental conditions of Kashmir, India
}

\author{
S. SHERAZ MAHDI ${ }^{*}$, RUKHSANA JAN ${ }^{1}$, INTIKHAB AALUM JEHANGIR ${ }^{2}$, \\ ASHAQ HUSSAIN ${ }^{2}$, M. ANWAR BHAT ${ }^{1}$, BHAGYASHREE DHEKALE ${ }^{3}$, LATIEF \\ AHMED $^{4}$, NAJEEBUL REHMAN SOFI ${ }^{2}$, S.A. BANGROO ${ }^{5}$, ASIF M.I. QURESHI ${ }^{6}$, OWAIS \\ ALI WANI ${ }^{5}$ and F.A. BAHAR ${ }^{1}$ \\ ${ }^{1}$ Division of Agronomy, ${ }^{2}$ Mountain Research Centre for Field Crops, ${ }^{3}$ Division of Agricultural Statistics, ${ }^{4}$ Dry Land \\ Agriculture Research Centre, ${ }^{5}$ Division of Soil Science, ${ }^{6}$ Division of Plant Breeding \& Genetics, Sher-e-Kashmir \\ University of Agricultural Sciences \& Technology of Kashmir, Shalimar, Srinagar, India \\ *Corresponding author email : syedapbau@skuastkashmir.ac.in
}

\begin{abstract}
A study was conducted in nine different topographical locations of Kashmir valley to know the perception of the farmers about climate change. Adaptation and mitigation strategies adopted by the farmers were also documented over a specified period viz., 1980-2019. Results from the observed data revealed warming trends in all seasons, however, winter and spring season temperatures have shown statistically significant increasing trends at the rate of $0.04^{\circ} \mathrm{C} /$ year. Analysis of seasonal and annual precipitation data shows a decreasing trend at the rate of $-4.5 \mathrm{~mm} /$ year. The farmers in the study areas had perceived that the climate has changed for the last four decades. Increasing temperature, frequent droughts and less snowfall were the main visual parameters experienced by the farmers. About $30-35 \%$ of the farmers have adopted different strategies by default to mitigate ill effects of climate change. However, the majority of the farmers $(70 \%)$ have not adopted any strategy to cope up with the impacts of climate change. Farmers ( $>90 \%$ ) have stressed on provision for an early warning system, timely supply of inputs, provision of financial support and nutrients for soil enrichment as viable options to combat the ill effects of climate change.
\end{abstract}

Key words: Climate change, field survey, farmer's perception, adaptation strategies

Warming due to climate change is now a reality as evident from the significant increase in the $\mathrm{CO}_{2}$ concentration (412.55 ppm as of August 2020) which has caused most of the warming and has contributed the most to climate change (NOAA, 2020). India's average temperature has risen by around $0.7^{\circ} \mathrm{C}$ during $1901-2018$ and is anticipated to rise by approximately $4.4^{\circ} \mathrm{C}$ by 2100 century (Krishnan et al., 2020). Rise in temperatures have also been perceived by the farmers of the country (Hussain et al., 2013), which is largely on account of GHG-induced warming, partially offset by forcing due to anthropogenic aerosols and changes in land use (Krishnan et al.,2020). Various studies suggest that most glaciers in the North Himalayan including Kashmir Himalayas (Kolahoi Peak: 5425 m; Harmukh Peak: 5143 m) and Amarnath Peak: $5186 \mathrm{~m}$ ) has reduced in mass and volume due to climate change (Romshoo et al., 2015; Wester et al., 2019).
Furthermore, proper quantification of clear knowledge of its causes in hilly terrains is subject to further studies.

Jammu \& Kashmir which constitutes an important part of the Great Himalayan range is also witnessing a significant influence of climate change on local weather in the form of shrinking and reducing glaciers, devastating floods, decreasing winter duration, and precipitation coupled with extended summer duration and elevated temperatures (Khan et al., 2019; Murtaza et al., 2017). Given the serious implication of climate change impacts, the Kashmir Valley is already suffering a deficit in food production by $40 \%, 30 \%$ in vegetable production, and $69 \%$ in oilseed production, putting the food security of UT at a greater risk (Bhat, 2019). Further, the impacts of climate change are likely to affect several other sectors like irrigated agriculture, horticulture, and 
hydropower capacity of the state (Sharma, 2015). All these factors supersede the interventions attempted by the policy forming institutions to address the adverse impact of climate change. Hence, it becomes imperative to make farmers aware of the problems of climate change and its impact that is creeping slowly but steadily. For this purpose, it is important to know the farmer's perception about changing climate and what adaption and mitigation measures have been taken by the farmers over time to counter its ill effects of climate change. Therefore, this study is aimed to seek the perception of farmers about climate change, to understanding observed trends and variability of local weather to determine the relationship between farmers perception and actual weather trends, which has an important bearing on determining the impact of climate change on state agricultureto suggest suitable management strategies for policymakers and the farming community at large.

\section{MATERIAL AND METHODS}

The study was carried out in nine different topographical locations (villages) falling in nine districts of Kashmir Valley (Fig. 1). The topographic and annual climatic features of these locations are given in Table 1. Since Kashmir Valley has rugged topography, and study locations have been purposely selected at three different altitudes of Kashmir Valley viz., 1. Low altitudes: $<1650 \mathrm{~m}$ (Wadura, Batpora, and Khudwani) 2. Mid altitudes:1650-1950 m (Pastuna, Sagam, Chandilura, Pombai, and Kalaroosa) and 3. High altitudes $>1950$ $\mathrm{m}$ (Hamchipora). At all locations, rice is grown as the main crop during summer (Kharif) season followed by rapeseed-mustard/ oats during winter (Rabi) season. A total of 1140 farmers were randomly selected from all nine locations (Fig. 2) and the questionnaire was set-up and provided to the selected farmers to figure out how far weather parameters like rainfall, minimum and maximum temperature has changed over time (40 years). Besides, information was also sought about the mitigation/ adaptation strategies adopted by farmers overtime to counter the ill effects of climate change. Feedback received from the farmers was analysed and the strategies they have adopted against the climate change impacts. The extent of similarity of the farmer's perception of the observed meteorological data was also taken into consideration. For the determination of observed climate change trends, long-term meteorological data (1980-2019) on parameters viz., maximum and minimum temperature and precipitation from the Indian Meteorological Department, Rambagh, Srinagar was also collected and analysed.

\section{RESULTS AND DISCUSSION}

\section{Trends of temperature and precipitation}

Maximum and minimum temperature: A significant increasing trend $(p=0.06)$ at a rate of $0.02^{\circ} \mathrm{C} /$ year of mean maximum temperature in Kashmir valley over 40 years was explained by a non-parametric Mann-Kendall statistical test (Fig. 3a). Data also specifies a substantial step jump in the year $1997(p=0.01)$ which demonstrates that there was a significant distinction in maximum temperature with recent decades (1997-2019) having higher ranges of maximum temperature than initial years (1980-1996) of the study period. Though there seem to be stages of increased and decreased annual temperatures, however this abrupt increase, particularly in mean maximum temperature is fascinating and needs further explanation. Conforming trends in annual mean minimum temperature expose an increasing rate of about $0.02^{\circ} \mathrm{C} /$ year, with the Mann-Kendall test presenting a statistically increasing trend ( $p=0.001$ ) (Fig. 3b), the year of change has been 1996, which is imitated by a significant abrupt increase.

Precipitation: Analysis of annual precipitation data for the period 1980-2019 for Kashmir Valley has shown a decreasing trend of $-4.50 \mathrm{~mm} / \mathrm{year}$ (Fig. 3c) with the maximum decrement recorded in the spring season $(-4.50$ $\mathrm{mm} /$ year) followed by $-0.30>-0.28>-0.06 \mathrm{~mm} /$ year for winter, autumn, summer season, respectively. A higher rate of decrease in precipitation was observed at the mountainous region, which was not conducive for delicate mountainous ecosystems especially for maintaining equilibrium in glaciers.

\section{Farmer's perception}

Critical weather parameter : The majority (50-70\%) of the farmers across all the locations expressed that rainfall is the critical factor that governs crop productivity (Fig. $4 a)$. About $30-50 \%$ of farmers opined that temperature 
Table 1: Topographic and annual climatic features of selected nine locations of the study

\begin{tabular}{|c|c|c|c|c|c|c|}
\hline $\begin{array}{c}\text { S. } \\
\text { NO. }\end{array}$ & $\begin{array}{l}\text { Location } \\
\text { name }\end{array}$ & Physiography & $\begin{array}{l}\text { Altitude } \\
\text { (mts) }\end{array}$ & $\begin{array}{c}\text { Max. } \\
\text { Temp } \\
\left({ }^{\circ} \mathrm{C}\right)\end{array}$ & $\begin{array}{l}\text { Min } \\
\text { Temp } \\
\left({ }^{\circ} \mathrm{C}\right)\end{array}$ & $\begin{array}{l}\text { Precipitation } \\
(\mathrm{mm})\end{array}$ \\
\hline 1 & Khudwani & Flood plain & 1590 & 19.31 & 6.44 & 1213 \\
\hline 2 & Pombai & Foothill & 1850 & 19.01 & 6.05 & 1145 \\
\hline 4 & Wadura & Flood plain & 1625 & 20.21 & 6.39 & 1085 \\
\hline 5 & Pastuna & Foothills & 1910 & 17.31 & 5.90 & 1213 \\
\hline 6 & Batpora & Flood plain & 1596 & 20.01 & 6.35 & 890 \\
\hline 7 & Hamchipora & Foothill & 2050 & 11.70 & 2.90 & 1480 \\
\hline
\end{tabular}

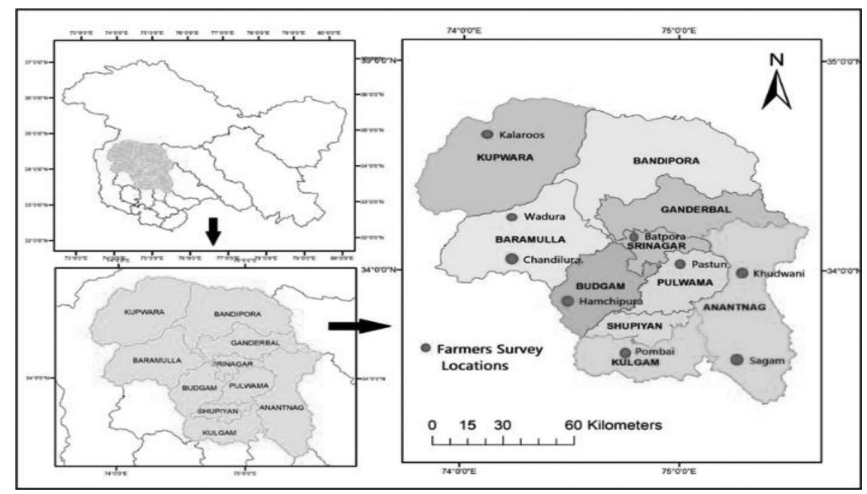

Fig. 1: Map of study locations falling in different districts of Kashmir Valley

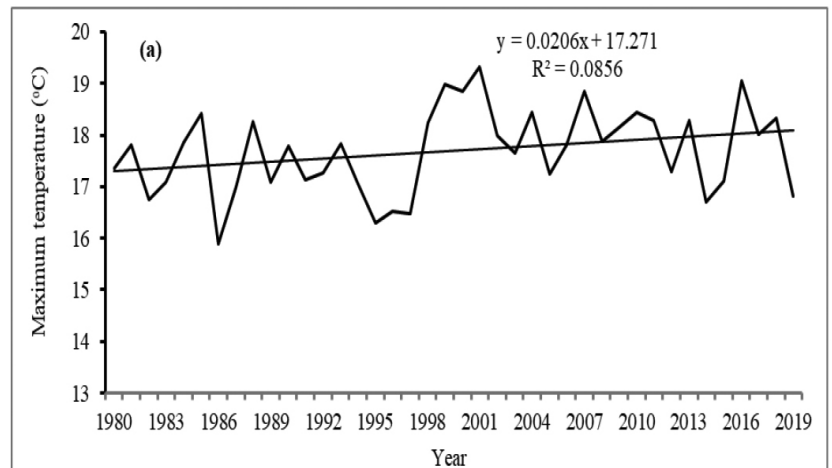

Year

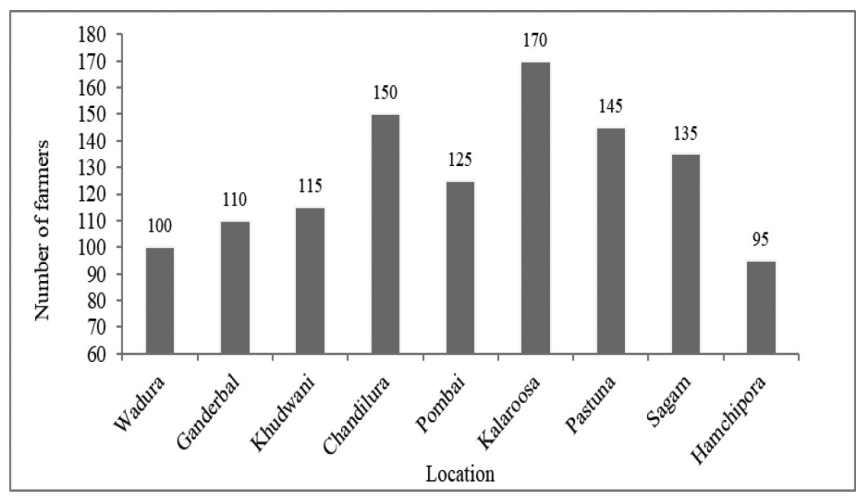

Fig. 2: Location wise number of farmers selected in this study
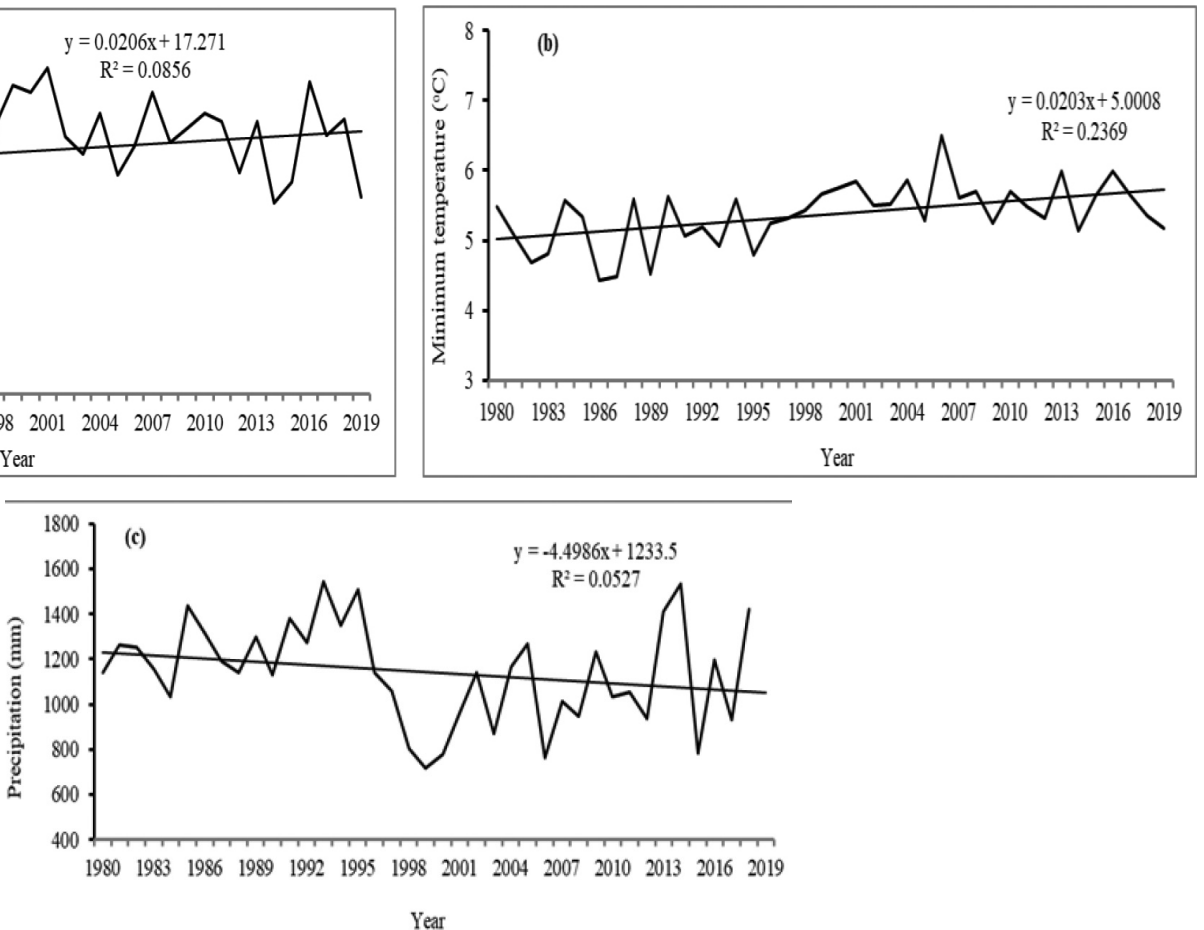

Year

Fig. 3 : Annual trends of a) maximum b) minimum temperatures and c) precipitation of Kashmir Valley 

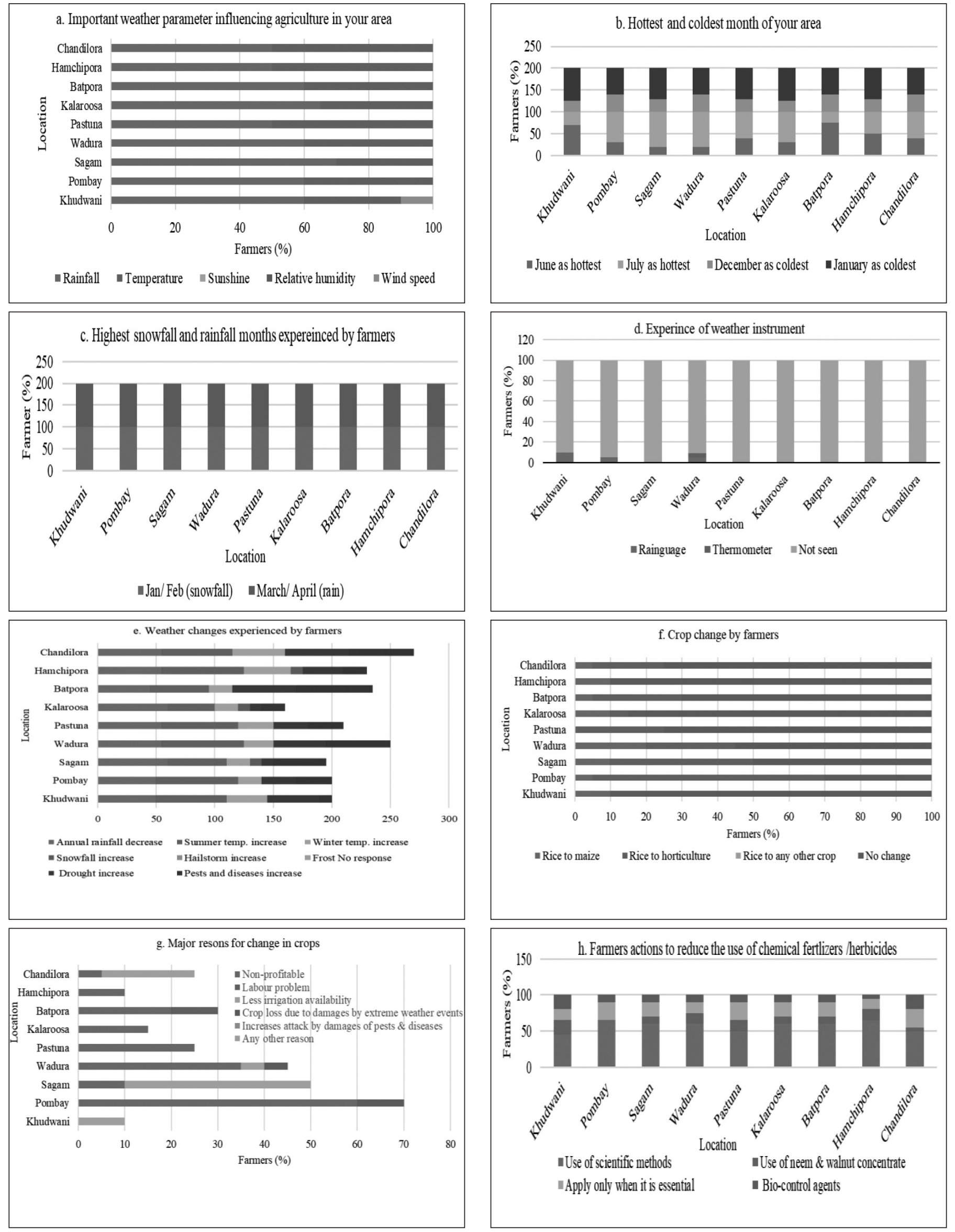

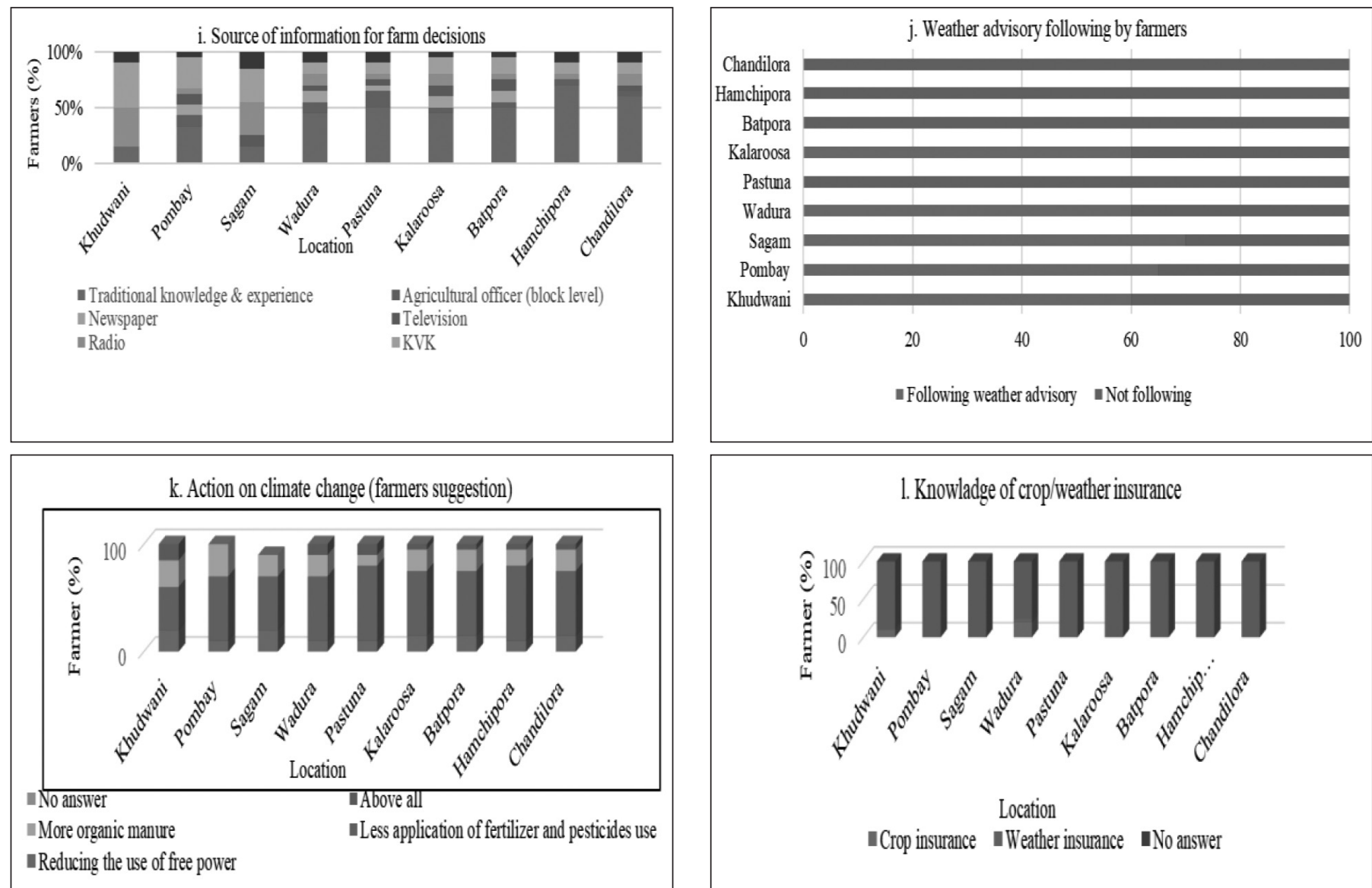

Fig.4 (a-l): Response of farmers (\%) on weather changes and its effect on agriculture at different topographical locations of Kashmir

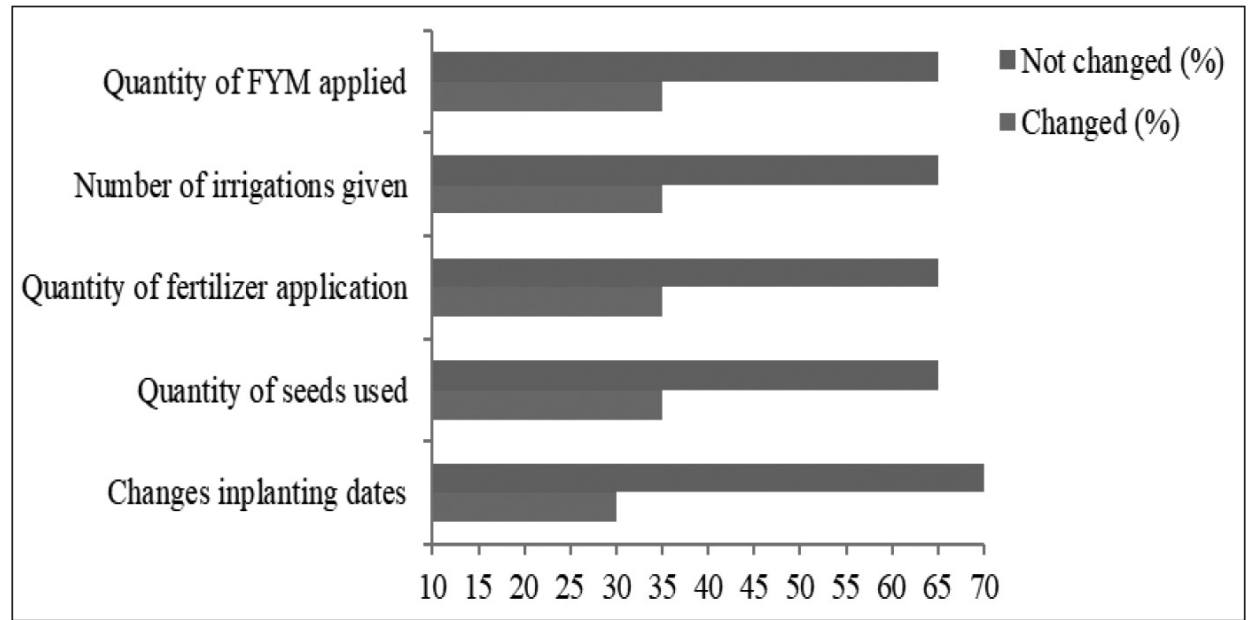

Fig. 5: Adaptation strategies/measures taken up by farmers to combat climate change

also has a significant impact on crop yield. None of the farmers could recognize the importance of sunshine and relative humidity on crop productivity. Only $10 \%$ of farmers from Khudwani had perceived the impact of wind speed on grain yields.

Temperature extremes : Farmers from different topographical locations recognized that June and July as the hottest and January as the coldest month (Fig. 4b). Farmers belonging to the area of Batpora (75\%) and Khudwani (70\%) identified June as their hottest month whereas, farmers hailing from remaining locations viz., Pastuna (60\%), Sagam (80\%), Pombai (70\%), Wadura (80\%), Chandilora (60\%), Kalaroosa $(70 \%)$ and 
Hamchipora (50\%) expressed that July month was the warmest month in their area. However, majority of the farmers $(60-75 \%)$ from all locations found January as coldest month of the year.

Precipitation (rainfall and snowfall) regimes : Farmers across nine locations of the Kashmir Valley were of the same view regarding the wettest month of their region (Fig. 4c). January and February months were identified as the highest snowfall months in Kashmir. Whereas, farmers experience the highest amount of rainfall in the month of March and April. Not a single farmer was able to answer about the amount of average annual rainfall in their region. It indicates the urgency to educate farmers about the distribution of this important climatic variable in all study areas.

Knowledge of the instrumentation : Majority of the farmers across nine locations stated that they have never visually experienced instruments that measure rainfall and temperature, except very small number of farmers from Khudwani (10\%), Pombay (5\%) and Wadura (5\%) (Fig. $4 d)$. This shows the importance of awareness programmes to educate farmers about meteorological instrumentation (raingauge and thermometer in particular) through various programmes.

Knowledge of climate/weather changes : The answer of the farmers to a question on the variation in the precipitation and temperature was overwhelming. (Fig. $4 \mathrm{e})$. Most of the farmers (45-60\%) from all locations felt that the annual rainfall has been declining in their region over time. About $40-70 \%$ of farmers across all locations informed that the summer temperatures have been also increasing. A reflection on the rise in winter temperatures was expressed by $20-45 \%$ of the farmers with major percentage from Hamchipora (40\%) and Chandilora (45\%). About $10 \%$ of farmers living in mid to higher altitudes of Kalaroosa, Sagam, and Hamchipora perceived an increase in snowfall. Only $10 \%$ of the farmers of Pastunacould notice the occurrence of hailstorms, however, an average of $35-36 \%$ of the farmers from all locations could notice that there has been an increase in occurrence of drought and pest and diseases. None of the farmers across all the locations could recognize an increase or decrease in frost.

Change and shift of crops : It was noticed that farmers have been trying to adapt their cropping system according to the inconsistency in weather parameters and as per the market demand by altering their farming/cropping systems (Fig.4f). The major crop change was found to be from rice to horticulture sector particularly in south Kashmir areas viz. Pomaby (65\%) and Sagam (45\%) compared to other locations of the study. Owing to less irrigation requirement, the horticulture fruit (apple) also fetches premium price in the market compared to rice and other crops. Despite this, most of the farmers (68\%) did not change their crops, but the farmers from all locations were unanimous in expressing the need to bring desirable changes for successful remunerative crop production for which reasons were attributed to non-profitability of existing crops (25\%), less irrigation availability (8\%) and crop damage due to extreme weather events (2\%) (Fig. $4 \mathrm{~g})$.

Farmers action on environmental erosion : Farmers across all the villages agreed to the fact that more applications of pesticides/insecticides harm the environment. Farmers from different locations viz., Khudwani (45\%), Pombai (65\%), Sagam (60\%), Wadura (60\%), Pastuna (50\%), Kalaroosa (60\%), Batpora (60\%), Hamchipora (65\%), Chandilora (50\%) opined that the use of scientific methods should be applied while applying the necessary herbicides and pesticides in crops. Farmers from Khudwani (20\%), Sagam (10\%), Wadura (15\%), Pastuna (15\%), Kalaroosa $(10 \%)$, Batpora (10\%), Hamchipora (15\%), Chandilora (5\%) also believed that use of biopesticides (like walnut or neem concentrate) should be applied to avoid the environmental problems. Some farmers (15-25\%) across all villages were in favour of need-based pesticide usage. Whereas, a small percentage of farmers $(5-20 \%)$ from all villages advocated the release of natural enemies (biocontrol agents) to control field pests and diseases (Fig. 4h).

Information source /advisory for farm decisions : Daily flow and reliability of the information play vital role in current agricultural operations. Information regarding field operations when collected leads us to the following conclusions (Fig. 4i):

- Indigenous knowledge has been the main source of information for farmers at Pombai (35\%), Wadura (45\%), Pastuna (50\%), Chandilora (60\%), and 
a. Creating awareness to farmers about appropriate adaptation measures against climate change

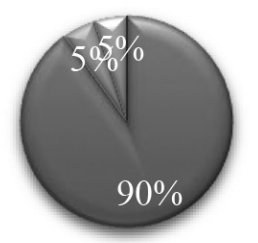

$\square$ Most important $\square$ Important $\square$ Less important

b. Development department should ensure supplying of production inputs at appropriate time

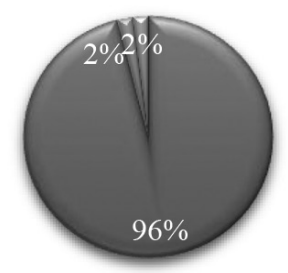

$\boldsymbol{\square}$ Most important $\boldsymbol{\nabla}$ Important $\boldsymbol{\nabla}$ Less important

c. Crop insurance for all crops

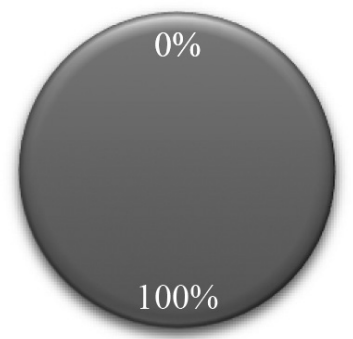

$\square$ Most important $\boldsymbol{\square}$ Important $\boldsymbol{\square}$ Less important

d. Minimum support price shuld be given to all crop produce based on cost of cultivation

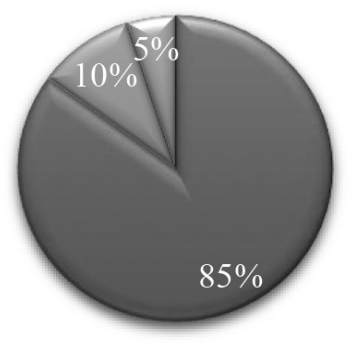

$\square$ Most important $\square$ Important $\square$ Less important
. e. Early warning has to be given to the farmers about environmental changes

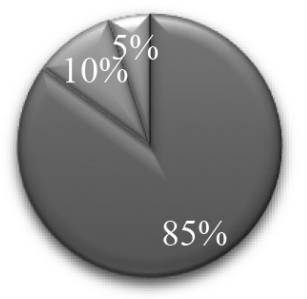

$\square$ Most important $\square$ Important

$\square$ Less important

f. Subsidies/compensation to be given for the crops loss to due to weather aberrations

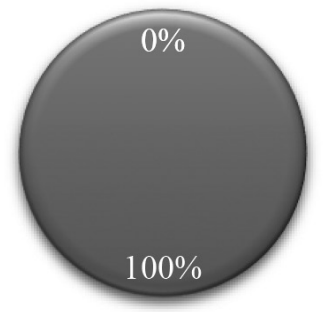

घMost important $\mathbf{\square}$ Important $\boldsymbol{\square}$ Less important

g. Financial support for soil nutrient enrichment

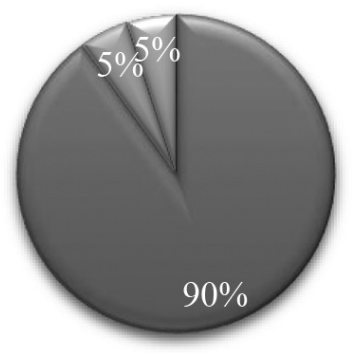

$\square$ Most important $\square$ Important $\square$ Less important

h. Requirement of agro-met advisory

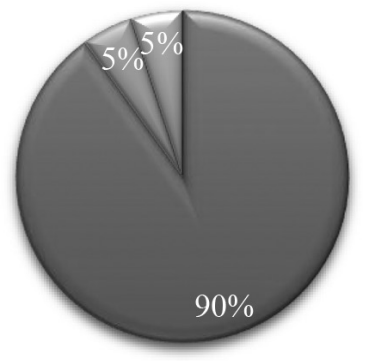

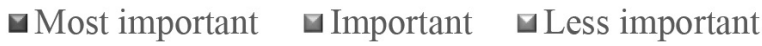

Fig. 6 (a-h) : Adaptation strategies/measures sought by farmers 
Hamchipora (70\%).

- $10-15 \%$ of the farmers of Pombai, Pastuna, and Wadura believed that officers from the line departments provide time to time information about new varieties of crops, fertilizer, irrigation schedule, and other field related operations.

- Newspapers (in the Urdu language) are the information source for $10 \%$ of the farmers from Kalaroosa, Batpora, Wadura, and Pombai.

- A television program in the local language (Kashmiri) is the knowledge source for $10 \%$ of the farmers of Sagam, Kalaroosa, and Batpora.

- Radio continues to be one of the information sources for the farmers of Sagam (30\%) and Khudwani (35\%)

- KVKs were the knowledge centers for the farmers of Sagam (30\%) and Khudwani (40\%).

Weather-based crop advisories : Agro-met advisory services of SKUAST-Kashmir (SAU) were found to be the prime source of information for Sagam, Wadura, Pombai, Kalaroosa, and Khudwani farmers. All selected farmers from an area like Batpora, Hamchipora, Pastuna, and Chandilora agreed that agromet advisories are not followed while carrying out agricultural activities. However, farmers from Sagam (70\%), Wadura (60\%), Pombai (65\%), Kalaroosa (60\%), and Khudwani (60\%) were found to follow agro-met advisories as provided by SAU (Fig. 4j).

Knowledge of climate change mitigation : Minimizing the application of fertilizers and pesticides are the major improvement methods stated by most of the farmers (40-70\%) across all locations to reduce climate change problems. About $10-30 \%$ of farmers from all topographical locations chose more organic manure application for mitigating the ill effects of climate change. A small percentage of farmers across all villages (10-20\%) believed that reducing the use of free power can mitigate the long-term impacts of climate change and can protect the environment (Fig. 4k).

Consciousness about weather/crop insurance schemes : Majority of the farmers across all locations did not respond about weather/crop insurance schemes. Only $20 \%$ and $10 \%$ farmers from Wadura and Khudwani respectively were aware of weather and crop insurance schemes (Fig.41). It is because farmers were found ignorant regarding weather/ crop insurance schemes. This warrants the importance of conducting the awareness program regarding crop insurance and other related schemes to cover risks associated with agriculture owing to the erratic behaviour of the climate and weather.

Adaptation and mitigation strategies : Adaptation strategies of nine different topographical locations revealed that $30 \%$ of farmers have changed planting dates against the adverse impact of climate change (Fig. 5). A total of $35 \%$ of the farmers agreed on an increase in the seed replacement rate, fertilizer application, irrigation numbers and quantity of FYM as a crop adaptation strategy against the changing climate.

Farmers expectations on mitigation : There were mixed but certain important measures highlighted by the farmers across all locations to address the issues of climate change. The measures as suggested by the farmers across the different topographical locations have been discussed as under and depicted in Fig. 6 (a-h).

- About $90 \%$ of farmers counted awareness programme on climate change as one of the prerequisites to upscale the mitigation strategies against the adverse effects of climate change (Fig. 6a). State agricultural universities through its KVKs should conducted theses awareness programs on regular basis to demonstrate the impact of climate change on agriculture.

- The majority of the farmers (96\%) favored the timely supply of farm inputs by the development department to the farmers as an important means to combat climate change (Fig. 6b). Line departmental officers have to play major role for timely supply of all inputs needed at farm level.

- All the farmers considered subsidies/ compensation and crop insurance scheme a successful strategy to make up at least cost of cultivation in case of any eventuality on account of any weather aberration (Fig. 6c). But at the same time, there is lack of awareness among the farmers about the current Govt. schemes 
like Pradhan Mantri Fasal Bima Yojana (PMFBY), Weather Based Crop Insurance Scheme (WBCIS) which has led to very low coverage of crops under insurance. It is therefore, argued that improving agricultural extension services is crucial for greater awareness about and thus take-up of crop insurance in Kashmir.

- $\quad$ The minimum support price (MSP) to be maintained and be extended for all crops was also viewed as one of the effective safeguard measures by $85 \%$ farmers against climate change (Fig. 6d). Income in the form of MSPs for all crops provides them secured income and also increases the likelihood of a farmer to practice more adaptive strategies to climate change.

- At different locations of the study, more than $85 \%$ of farmers also viewed accurate early weather warnings system at block level and agro-met advisories services as one of the most viable strategies for preparedness against climate risks (Fig. $6 \mathrm{~h} \&$ e) Although Agromet field unit, SKUAST-K in collaboration with India Meteorological Department issues timely weather warnings and advisories, but most of farmers show reluctance in following same while performing their routine farm operations, where it calls for conduction of more awareness program on the usage of this important weather information at village level.

- In addition to above, providing financial support for soil nutrient enrichment was also viewed as most important assistance against climate change by the $90 \%$ of farmers across the different locations of study (Fig. 6g). Whereas government compensations and subsidies to farmers in the event of their crop failure due to any calamity was also considered as strategic measure against climate risks (Fig 6f).

\section{CONCLUSION}

This study has shown that majority of farmers across all topographical locations have perceived a change in climatic variables over last three to four decades through increasing summer and winter temperatures, frequent droughts, reduced precipitation and drier winters. This was also observed from analysis of longterm weather data (1980-2019), where maximum and minimum temperatures have shown increasing trend of $0.02^{\circ} \mathrm{C} /$ year and precipitation reduction of $-4.50 \mathrm{~mm} /$ year. Against this change in climate, few farmers at all locations have implemented some crop adaptation and mitigation strategies to avert climate change impacts and to increase the crop productivity in their respective regions. But there is urgent need for empowerment of the farmers to rationalize the climate smart farm activities against climate change and to increase farm output. Therefore, it is suggested that awareness programs should be organized regarding the causes, impacts, and mitigation of climate change. This paper also calls for the government to infuse funds and develop human resources that will provide expertise measures to build up resilient agriculture in the picture of inevitable climate change.

\section{ACKNOWLEDGEMENT}

The authors gratefully acknowledge financial support from ICAR, CRIDA, NICRA, Hyderabad. The authors also thank all the farmers for their cooperation and sharing information during the field survey.

Conflict of Interest Statement: The author(s) declare(s) that there is no conflict of interest.

Disclaimer: The contents, opinions, and views expressed in the research article published in the Journal of Agrometeorology are the views of the authors and do not necessarily reflect the views of the organizations they belong to.

Publisher's Note: The periodical remains neutral with regard to jurisdictional claims in published maps and institutional affiliations.

\section{REFERENCES}

Bhat, B.A. (2019). Will climate change bring back the age of famines in Kashmir? Down to Earth (Fortnightly Magazine), New Delhi, India. 10p.

Hussain, R. Dutta, K. K. Tamuly, D. Deka R. L. and Khanikar P. G. (2013). Farmer's perception of climate change impact and its mitigation in Golaghat district of Assam. J. Agrometeorol., 15 (Special Issue-II):203-208.

Khan, J. N., Jillani, A., Ali, S.R., Rashid, Z., Rehman, 
Z. and Ashraf, I. 2019. Modeling climate change in cold arid regions of north western Himalayas using multiple linear regression modelling. $J$. Agrometeorol., 21(4): 474-479

Krishnan, R., Sanjay, J., Gnanaseelan, C., Mujumdar, M., Kulkarni, A., Chakraborty, S. (2020) Assessment of Climate Change over the Indian Region: A Report of the Ministry of Earth Sciences (MoES), Government of India. Springer Nature.

Murtaza, K.O., Romshoo, S.A. (2015). Recent glacier changes in the Kashmir alpine Himalayas, India. Geocarto Internat., 32:188-205.

NOAA, National Centers for Environmental Information, State of the Climate: Global Climate (2020). Published online Aug 2020, online:www.ncdc. noaa.gov/sotc/global/202007.

Romshoo, S.A., Dar, R. A., Rashid, I., Marazi, A., Ali, N., Zaz, S.N.J.A., (2015). Implications of shrinking cryosphere under changing climate on the streamflow in the Lidder catchment in the Upper Indus Basin, India.Arctic, Antarctic, and Alpine Research, 47:627-44.

Sharma, O.M. (2015). Climate change and concerns of J\&K. ENVIS New Letter, J\&K ENVIS Centre Department of Ecology, Environment \& Remote Sensing Jammu\& Kashmir (Pub.), 4p.

Wester, P., Mishra, A., Mukherji, A., Shrestha, A.B [eds]. (2019). The Hindu Kush Himalaya Assessment: Mountains, Climate change, Sustainability and People: Pub: Springer Nature, 1-16 of 578. Online: https://www.springer.com/gp book/ 9783319922874 